\title{
Experimental Results of a Single-Phase Shunt Active Filter Prototype with Different Switching Techniques
}

\author{
Pedro Neves, Gabriel Pinto, Ricardo Pregitzer, Luís Monteiro, M. J. Sepúlveda Freitas, João L. Afonso \\ Industrial Electronics Department \\ University of Minho \\ Guimarães, Portugal \\ Email: \{pneves|gpinto|rpregitzer|lmonteiro|manuel.freitas|jla\}@dei.uminho.pt
}

\begin{abstract}
This paper presents experimental results obtained with a developed single-phase shunt active power filter laboratory prototype operating with different switching techniques. This active filter can compensate harmonic currents and power factor in single-phase electric installations. Its power circuit is based on a two-leg IGBT inverter, with a single capacitor in the dc side, and an inductor in the ac side. Its control system is based on a simple stratagem that enables the use of the traditional Theory of Instantaneous Reactive Power (p-q Theory), originally developed to three-phase power systems, in single-phase systems. The experimental results are obtained for the active filter operating with two different switching techniques: Periodic Sampling (with variable switching frequency) and Pulse Width Modulation (with constant switching frequency) for two different frequencies $(8 \mathrm{kHz}$ and $16 \mathrm{kHz}$ ). Three different types of loads are used: linear RL load, rectifier with RL load, and rectifier with RC load.
\end{abstract}

Keywords - Single-Phase Shunt Active Power Filter, p-q Theory, Instantaneous Reactive Power Theory, Harmonics Compensation, Power Factor Correction, Power Quality.

\section{INTRODUCTION}

The vast use of power electronics converters and other non-linear loads has increased the number and the severity of power quality problems in the electric power systems. Problems like harmonics, inter-harmonics, flicker, notches, sags, swells, momentary interruptions, and others, can cause destruction or degradation of components, and malfunction of equipments based in microelectronic circuits, that are very sensitive to disturbances in the power supply. In order to minimize the impact of these power quality problems, Gyugi and Strycula introduced the concept of Active Power Filters in 1976 [1]. These types of active filters, contrarily to the passive ones, like RC and LC filters, have the capability to dynamically and automatically adapt to the conditions of the power system in order to compensate some of its problems. Although the most significant need for compensating power quality problems occurs in three-phase systems of industrial consumers, where the production costs and the pursuit for quality can be very high, nowadays, single-phase residential and commercial facilities also require measures to assure the quality of operation of their electrical installations. The increasing usage of computers, and other sensitive equipments at home and office environments, which are normally supplied by single-phase systems, makes important to develop singlephase active filters to solve power quality problems of these types of electrical installations.

\section{CONTROL STRATEGY}

In 1983, Akagi et al. [2, 3] proposed the "The Generalized Theory of the Instantaneous Reactive Power in Three-Phase Circuits", also known as "Theory of Instantaneous Reactive Power", or p-q Theory. It was initially developed for threephase three-wire systems, with a brief mention to systems with neutral wire. Later, Watanabe et al. [4] and Aredes et al. [5] extended it to three-phase four-wire systems. This theory is based on instantaneous values in three-phase power systems with or without neutral wire, and is valid for steady-state or transitory operation. The $\mathrm{p}-\mathrm{q}$ theory consists of an algebraic transformation (Clarke transformation) of the three-phase voltages and currents in the $a-b-c$ coordinates to the $\alpha-\beta-0$ coordinates according to the expression (1), where $x$ can be voltages $(v)$ or currents $(i)$.

$$
\left[\begin{array}{l}
x_{0} \\
x_{\alpha} \\
x_{\beta}
\end{array}\right]=\sqrt{2} / 3 \cdot\left[\begin{array}{ccc}
1 / \sqrt{2} & 1 / \sqrt{2} & 1 / \sqrt{2} \\
1 & -1 / 2 & -1 / 2 \\
0 & \sqrt{3} / 2 & -\sqrt{3} / 2
\end{array}\right] \cdot\left[\begin{array}{l}
x_{a} \\
x_{b} \\
x_{c}
\end{array}\right]
$$

After the transformation, the $\mathrm{p}-\mathrm{q}$ theory components are calculated using the expressions (2-4), where $p$ is the instantaneous real power, $q$ is the instantaneous imaginary power (by definition) and $p_{0}$ is the instantaneous zero-sequence power.

$$
\begin{aligned}
& p=v_{\alpha} \cdot i_{\alpha}+v_{\beta} \cdot i_{\beta} \\
& q=v_{\beta} \cdot i_{\alpha}-v_{\alpha} \cdot i_{\beta} \\
& p_{0}=v_{0} \cdot i_{0}
\end{aligned}
$$

Normally, only the average value of the instantaneous real power $(p)$ is desirable and the other power components can be compensated using a shunt active filter. In order to calculate the reference currents that the active filter should inject it is necessary to separate the desired components from the undesired ones. The undesired components, $p_{x}$ and $q_{x}$, are used to determinate the compensation currents in the $\alpha-\beta-0$ coordinates by the expressions $(5,6)$.

$$
\left[\begin{array}{c}
i_{c \alpha} \\
i_{c \beta}
\end{array}\right]=\frac{1}{v_{\alpha}^{2}+v_{\beta}^{2}} \cdot\left[\begin{array}{cc}
v_{\alpha} & v_{\beta} \\
-v_{\beta} & v_{\alpha}
\end{array}\right] \cdot\left[\begin{array}{c}
p_{x} \\
q_{x}
\end{array}\right]
$$




$$
i_{c 0}=i_{0}=\frac{1}{\sqrt{3}} \cdot\left(i_{a}+i_{b}+i_{c}\right)
$$

The compensation currents in the $a-b-c$ coordinates are determined by applying the inverse Clarke transformation to the currents in the $\alpha-\beta-0$ coordinates, as demonstrated in (7).

$$
\left[\begin{array}{l}
i_{c a} \\
i_{c b} \\
i_{c c}
\end{array}\right]=\sqrt{2 / 3} \cdot\left[\begin{array}{ccc}
1 / \sqrt{2} & 1 & 0 \\
1 / \sqrt{2} & -1 / 2 & \sqrt{3} / 2 \\
1 / \sqrt{2} & -1 / 2 & -\sqrt{3} / 2
\end{array}\right] \cdot\left[\begin{array}{c}
i_{c 0} \\
i_{c \alpha} \\
i_{c \beta}
\end{array}\right]
$$

The original $p-q$ Theory is only applicable to three-phase systems. The stratagem used to apply this theory to a singlephase system consists in creating two virtual currents and two virtual voltages that have the same magnitude as the measured current and voltage but are shifted $\pm 120^{\circ}$ to perform a virtual three-phase system. After this operation the methodology is the same as applied in real three-phase systems. At the end of the calculations only one of the three reference currents is used to control the inverter. The virtual voltages and currents were created using arrays in the digital control system, that was implemented on a Texas Instruments TMS320F2812 DSP.

In addition to the instantaneous power components defined by the $\mathrm{p}-\mathrm{q}$ Theory, there is also a component, $p_{\text {reg }}$, which is used to regulate the capacitor voltage in the dc side of the Shunt Active Power Filter. This regulation is done with a proportional controller and the error between the reference voltage $\left(V_{r e f}\right)$ and the voltage measured at the dc side of the inverter $\left(v_{d c}\right)$. The component $p_{\text {reg }}$ is included in the value of $p_{x}$.

$$
p_{\text {reg }}=k_{p}\left(V_{r e f}-v_{d c}\right)
$$

\section{HARDWARE}

The power circuit of the Single-Phase Shunt Active Filter is constituted by a two-leg, 4 IGBTs (with antiparallel diodes), Voltage Source Inverter (VSI). The dc side of the inverter uses a single capacitor (with $4.7 \mathrm{mF}$ capacitance), and between the inverter and the point of connection to the electric grid is used an inductor (with $5 \mathrm{mH}$ inductance) to decrease the ripple of the compensating current produced by the active filter. To assure that the comparison of the results obtained with different switching techniques is performed in equal conditions, it is not used any kind of passive elements to filter the switching frequency harmonics.

The measuring signals necessary to the control system were obtained with voltage and current Hall effect sensors: ac voltage system $\left(v_{a c}\right)$, inverter dc side voltage $\left(v_{d c}\right)$, source current $\left(i_{S}\right)$, load current $\left(i_{L}\right)$, and active filter current $\left(i_{F}\right)$. In Fig. 1 it is possible to see a simple diagram of the developed Single-Phase Shunt Active Filter laboratory prototype.

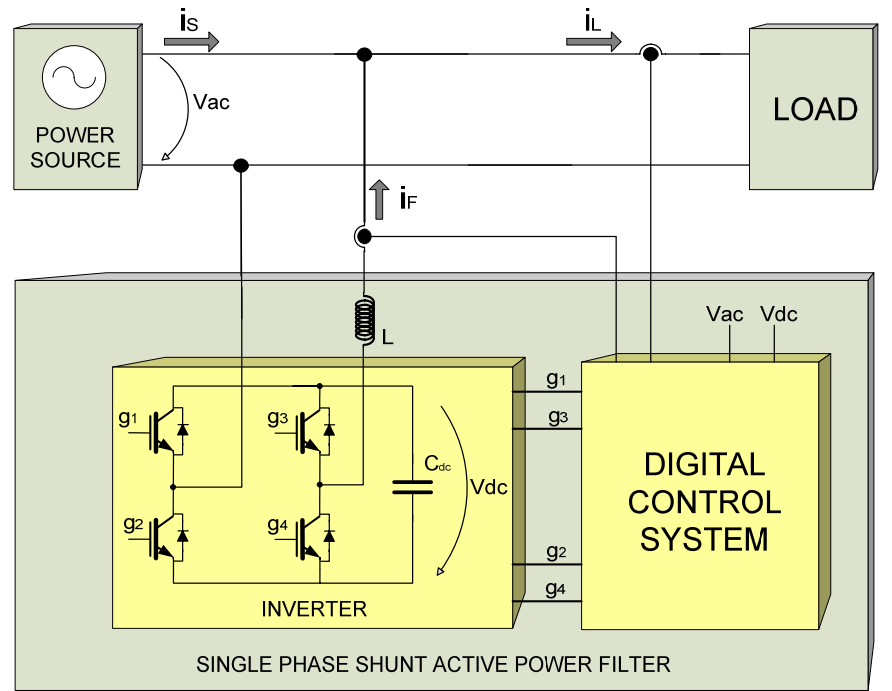

Fig. 1. Single-Phase Shunt Active Filter Diagram

The switching control of the IGBTs of the inverter has been done with two different techniques:

- Periodic Sampling - It is a very simple technique, but that does not work with a fixed switching frequency, although establishes an upper frequency limit, which in this work was set to $15 \mathrm{kHz}$.

- PWM (Pulse Width Modulation) - It allows working with a fixed predetermined switching frequency, and a variable duty cycle. In this work two different frequencies were used: $8 \mathrm{kHz}$ and $16 \mathrm{kHz}$. [6]

\section{EXPERIMENTAL RESULTS}

This item shows experimental results for the Single-Phase Shunt Active Filter prototype working with the above described switching techniques for three different types of single-phase loads: linear RL load, full bridge rectifier with a series RL load, and full bridge rectifier with a parallel RC load. For each load it is presented the voltage system $\left(v_{a c}\right)$ and the source current $\left(i_{S}\right)$ first with the shunt active filter turned off, and then with the active filter turned on, operating with Periodic Sampling, $P W M$ with $8 \mathrm{kHz}$ and $P W M$ with $16 \mathrm{kHz}$. For the shunt active filters turned on it is also shown the compensation current produced by the active filter $\left(i_{F}\right)$ and the reference current $\left(i_{r e f}\right)$, that corresponds to the compensation current calculated by the digital control system of the active filter.

Tables 1, 2 and 3 present values that permit verify the performance of the Single-Phase Shunt Active Filter with the three different switching techniques, relatively to the operation of the power system without compensation, for the three different types of loads. The table presents the True RMS source current value, the percentage of Total Harmonic Distortion (THD) of the source current, the Power Factor (PF total power factor, considering the harmonics), and the value of $\cos \varphi$ (fundamental power factor). All these values were 
measured with the equipment FLUKE 43B Power Quality Analyzer. The THD was calculated considering harmonics until the $49^{\text {th }}$ order.

\section{A. RL Load}

This load consists of a $31 \mathrm{mH}$ inductor with $0.7 \Omega$ resistance. Fig. 2 shows the waveforms obtained in the experimental results performed with this type of load.

From Fig. 2 and Table 1 it is possible to conclude that all three approaches correct the power factor successfully to unity or very close to it. Ought to that, the current source RMS value decreases considerably, however, this value is higher for the operation with $P W M-16 \mathrm{kHz}$. It happens because the Shunt Active Filter losses are greater in this case, because the IGBTs switch at a higher frequency. On the other hand, the operation with $P W M-16 \mathrm{kHz}$ allows the better results regarding the source current THD value.

TABLE I

VALUES FOR OPERATION WITH RL LOAD

\begin{tabular}{|l|c|c|c|c|}
\hline & Is_rms & THD & PF & $\cos \varphi$ \\
\hline $\begin{array}{l}\text { Without } \\
\text { Compensation }\end{array}$ & $6.64 \mathrm{~A}$ & $1.5 \%$ & 0.1 & 0.11 \\
\hline $\begin{array}{l}\text { Periodic } \\
\text { Sampling }\end{array}$ & $2.57 \mathrm{~A}$ & $4.2 \%$ & 0.98 & 0.99 \\
\hline$P W M-8 \mathrm{kHz}$ & $2.61 \mathrm{~A}$ & $3.5 \%$ & 0.98 & 1 \\
\hline $\begin{array}{l}P W M- \\
16 \mathrm{kHz}\end{array}$ & $3.54 \mathrm{~A}$ & $2.9 \%$ & 1 & 1 \\
\hline
\end{tabular}

B. Full Bridge Rectifier with a Series RL Load

This load consists of a four diodes full bridge rectifier with an inductor in series with a resistor in the de side, totalizing $31 \mathrm{mH}, 7.7 \Omega$. Fig. 3 shows the waveforms obtained in the experimental results performed with this type of load.

It can be seen, from Fig. 3 and Table II that the shunt active filter compensates the current distortion successfully in all cases, with slightly different performances. Once more the compensated source current is higher for the $P W M-16 \mathrm{kHz}$ approach, since the inverter switching losses are greater. However with this load the best THD result occurred for the Periodic Sampling approach (although the difference was small). By compensating the harmonics currents, all approaches turned the total power factor close to unity.

TABLE II

VALUES FOR OPERATION WITH RECTIFIER WITH RL LOAD

\begin{tabular}{|l|c|c|c|c|}
\hline & Is_rms & THD & PF & $\cos \varphi$ \\
\hline $\begin{array}{l}\text { Without } \\
\text { Compensation }\end{array}$ & $7.72 \mathrm{~A}$ & $31.5 \%$ & 0.93 & 0.98 \\
\hline $\begin{array}{l}\text { Periodic } \\
\text { Sampling }\end{array}$ & $9.3 \mathrm{~A}$ & $3.7 \%$ & 0.99 & 1 \\
\hline $\begin{array}{l}\text { PWM- } \\
8 \mathrm{KHz}\end{array}$ & $9.21 \mathrm{~A}$ & $5.8 \%$ & 0.99 & 1 \\
\hline $\begin{array}{l}\text { PWM - } \\
16 \mathrm{KHz}\end{array}$ & $11.0 \mathrm{~A}$ & $4.3 \%$ & 0.99 & 1 \\
\hline
\end{tabular}

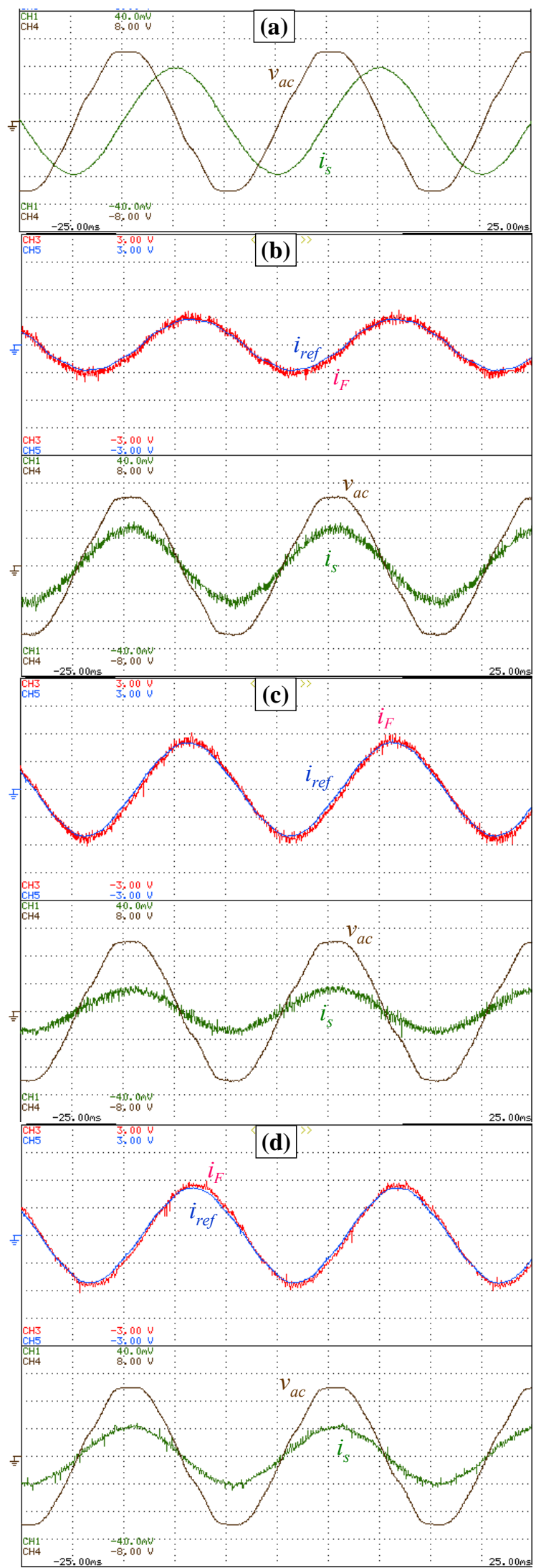

Fig. 2. Operation with RL load: (a) Without compensation; (b) Active filter with Periodic Sampling;

(c) Active filter with $P W M-8 \mathrm{kHz}$; (d) Active filter with $P W M-16 \mathrm{kHz}$ 


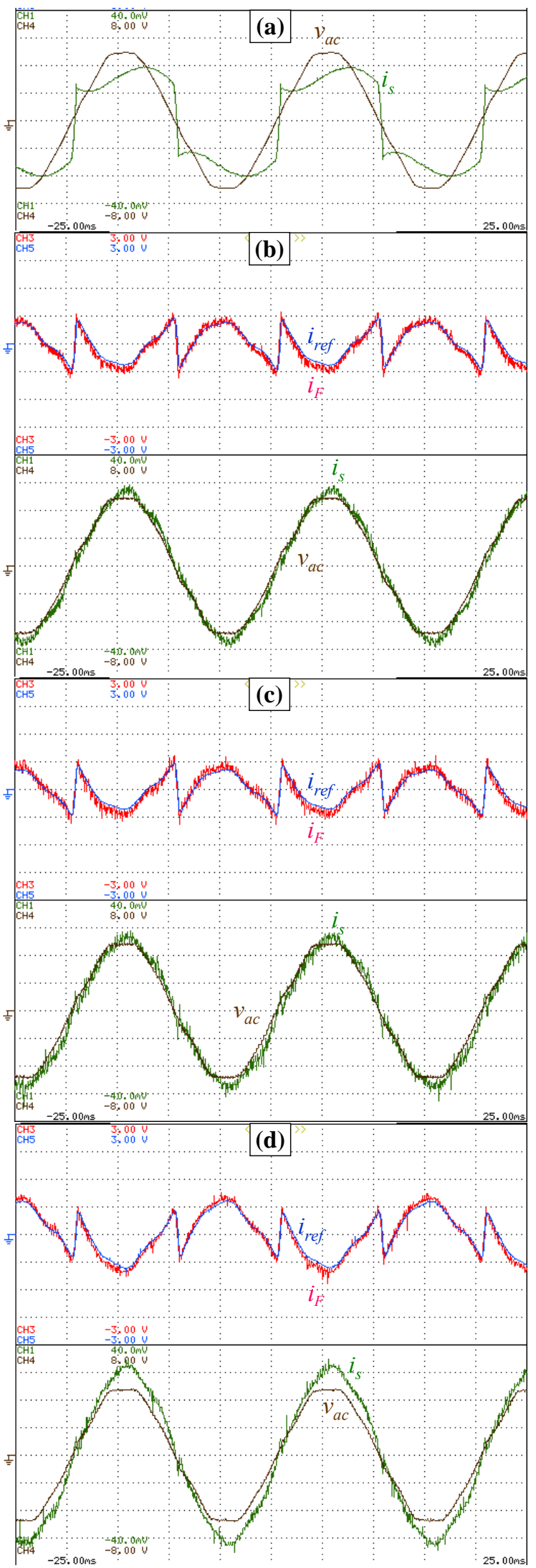

Fig. 3. Operation with rectifier with RL load: (a) Without compensation; (b) Active filter with Periodic Sampling;

(c) Active filter with $P W M-8 \mathrm{kHz}$; (d) Active filter with $P W M-16 \mathrm{kHz}$

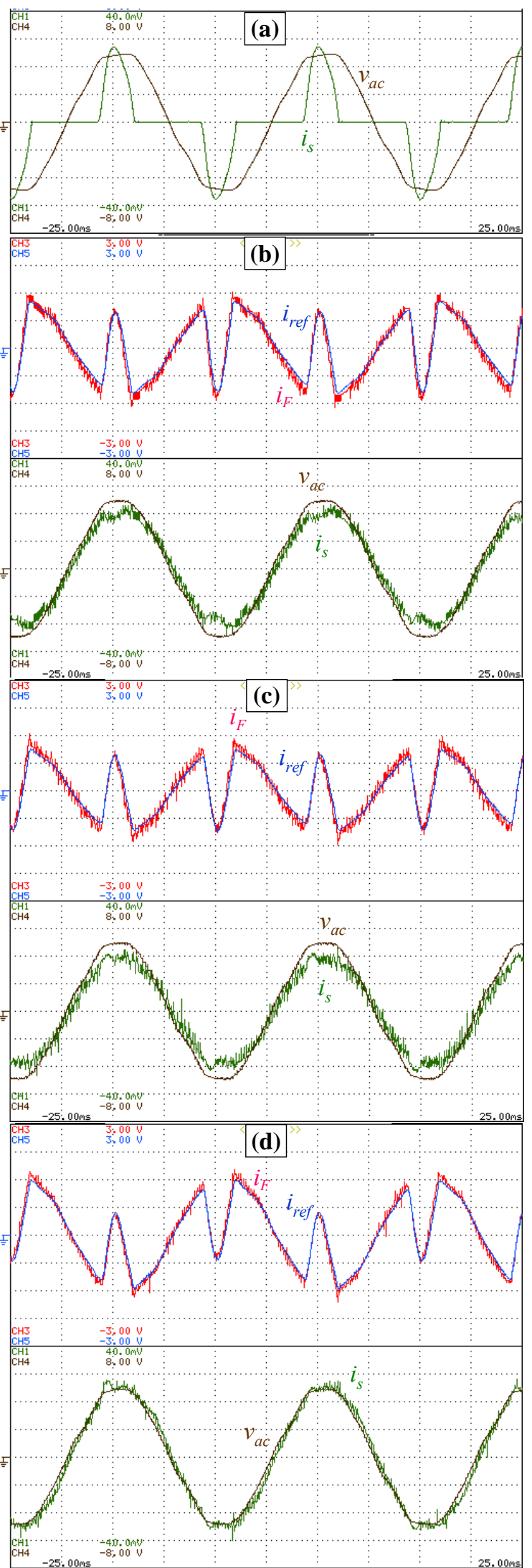

Fig. 4. Operation with rectifier with RC load: (a) Without compensation; (b) Active filter with Periodic Sampling;

(c) Active filter with $P W M-8 \mathrm{kHz}$; (d) Active filter with $P W M-16 \mathrm{kHz}$ 


\section{Full Bridge Rectifier with a Parallel RC Load}

Consists of a four diodes full bridge rectifier with a capacitor in parallel with a resistor in the dc side. The capacitance is $1.9 \mathrm{mF}$, and the resistance is $31 \Omega$. Fig. 4 shows the waveforms obtained in the experimental results performed with this type of load.

As can be seen from Fig. 4 and Table III, the shunt active filter compensates the current distortion successfully in all cases, but the performance with the three switching approaches is considerably different. The compensated source current is significantly higher for the $P W M-16 \mathrm{kHz}$ approach than for the other ones (30\% higher), what once more happens because of the increased inverter switching losses. Conversely, considering the source current THD value, the $P W M-16 \mathrm{kHz}$ approach presents a much better performance than the others. Again, by compensating the harmonics currents, all approaches turned the total power factor close to unity.

TABLE III

VALUES FOR OPERATION WITH RECTIFIER WITH RC LOAD

\begin{tabular}{|l|c|c|c|c|}
\hline & Is_rms & THD & PF & $\cos \varphi$ \\
\hline $\begin{array}{l}\text { Without } \\
\text { Compensation }\end{array}$ & $5.88 \mathrm{~A}$ & $68.5 \%$ & 0.72 & 1 \\
\hline $\begin{array}{l}\text { Periodic } \\
\text { Sampling }\end{array}$ & $6.99 \mathrm{~A}$ & $6.2 \%$ & 0.99 & 1 \\
\hline $\begin{array}{l}\text { PWM- } \\
8 \mathrm{KHz}\end{array}$ & $6.96 \mathrm{~A}$ & $5.9 \%$ & 0.99 & 1 \\
\hline $\begin{array}{l}P W M- \\
16 \mathrm{KHz}\end{array}$ & $9.05 \mathrm{~A}$ & $4.0 \%$ & 0.99 & 1 \\
\hline
\end{tabular}

\section{Spectrum Analysis of the load and system currents under} non-linear loads

The spectrum analysis was made by means of a Fluke $43 B$ Power Quality Analyzer, as illustrated in the following figures (Fig. 5 - Fig. 12). In Fig. 5 and Fig. 9, are illustrated the harmonic components of the current drained by two full bridge rectifiers, one with a parallel $\mathrm{RC}$ load and the other with a series RL load. As expected, currents drained by these loads present zero-sequence components plus harmonics resulted from the equation $(6 \mathrm{k} \pm 1)$, for $\mathrm{k} \geq 1$. Moreover, it can be observed a higher presence of zero-sequence components in the current drained by a full bridge rectifier with a parallel $\mathrm{RC}$ load.

The system currents compensated by the shunt active filter with a load represented by a full bridge rectifier with a parallel RC load are illustrated in figures (Fig. 6 - Fig. 8). In figures (Fig. 10 - Fig. 12) are observed system currents compensated by the shunt active filter with a load represented by a full bridge rectifier with a series RL load. As it can be noted the harmonic components are minimized, even though small components of fifth, seventh and eleventh harmonics, plus a small amount of the third harmonic component, were not compensated.

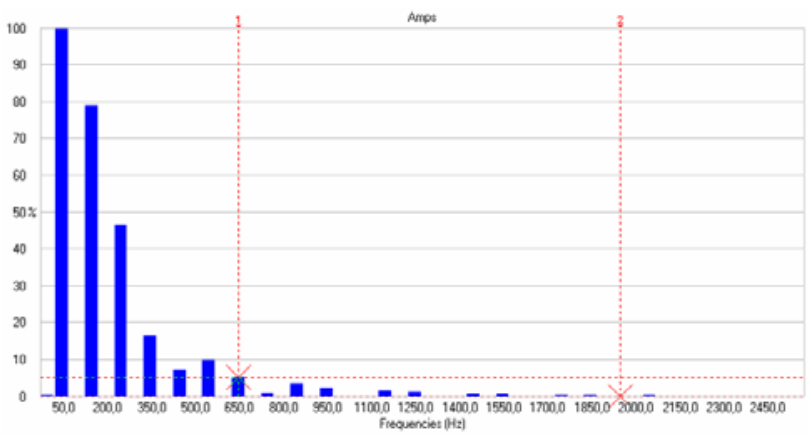

Fig. 5. Spectrum analysis of the current drained by a full bridge rectifier with a parallel RC load

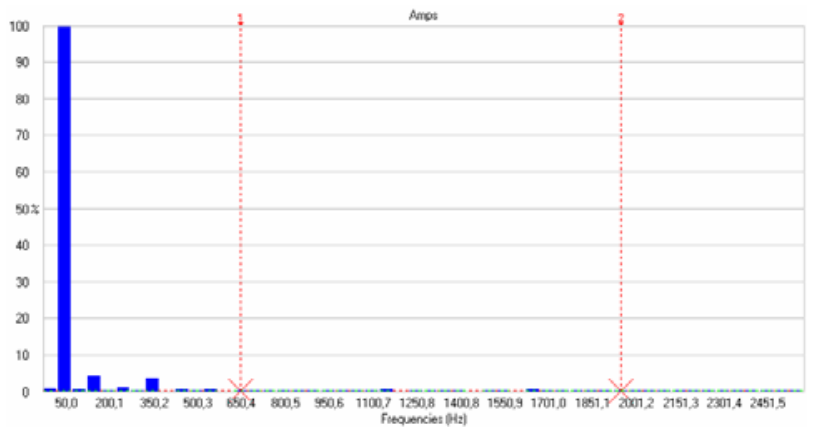

Fig. 6. Spectrum analysis of the compensated system current with Periodic Sampling switching technique (full bridge rectifier with a parallel $\mathrm{RC}$ load)

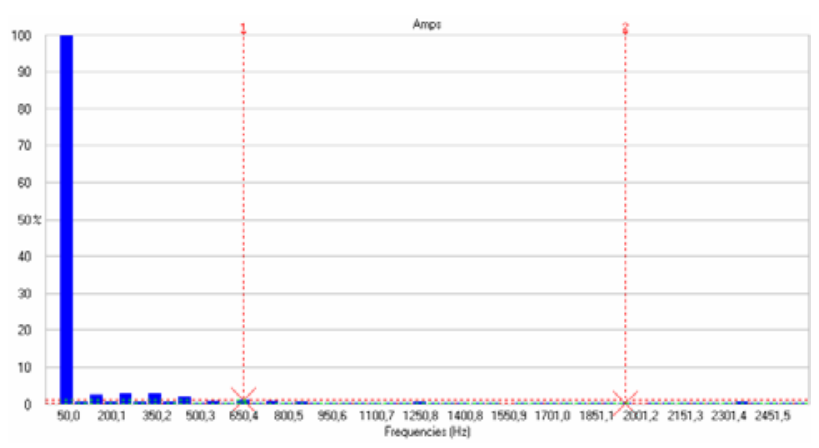

Fig. 7. Spectrum analysis of the compensated system current with $P W M-8 \mathrm{kHz}$ switching technique (full bridge rectifier with a parallel $\mathrm{RC}$ load)

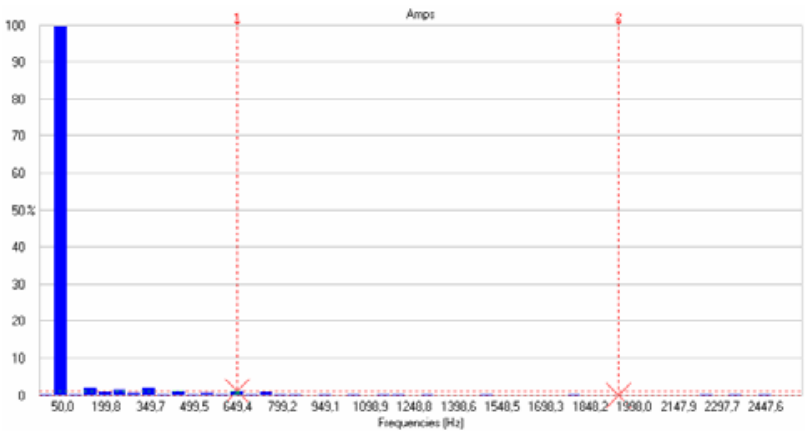

Fig. 8. Spectrum analysis of the compensated system current with $P W M-16 \mathrm{kHz}$ switching technique (full bridge rectifier with a parallel $\mathrm{RC}$ load) 


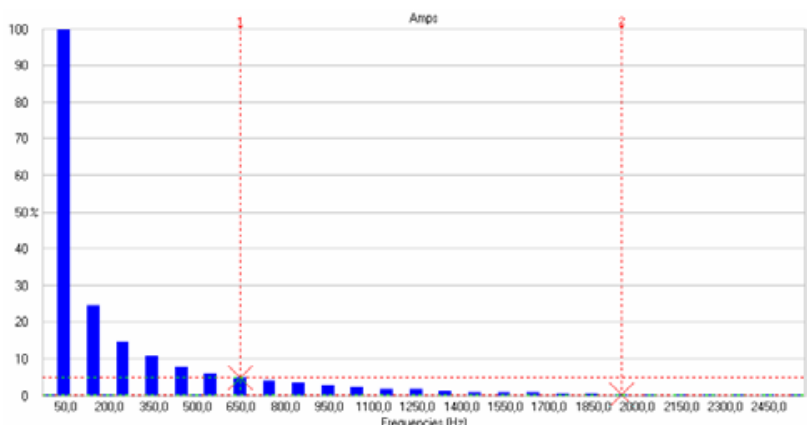

Fig. 9. Spectrum analysis of the current drained by a full bridge rectifier with a series RL load

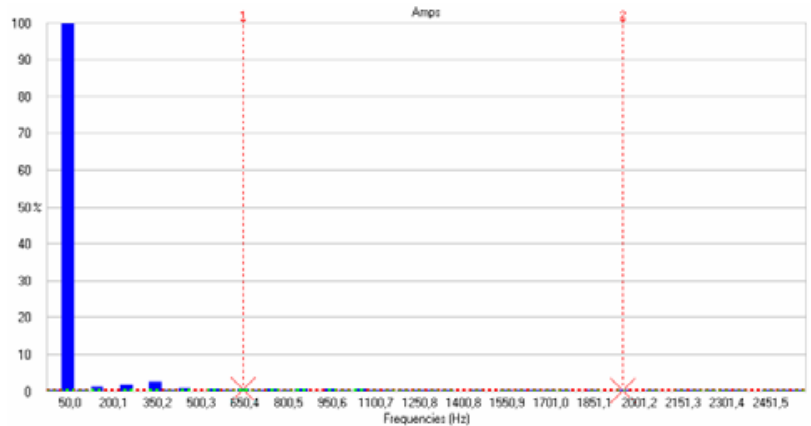

Fig. 10. Spectrum analysis of the compensated system current with Periodic Sampling switching technique (full bridge rectifier with a series RL load)

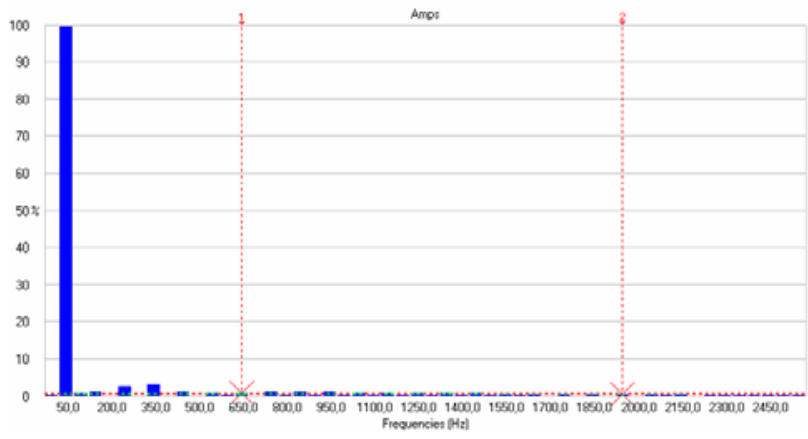

Fig. 11. Spectrum analysis of the compensated system current with $P W M-8 \mathrm{kHz}$ switching technique (full bridge rectifier with a series RL load)

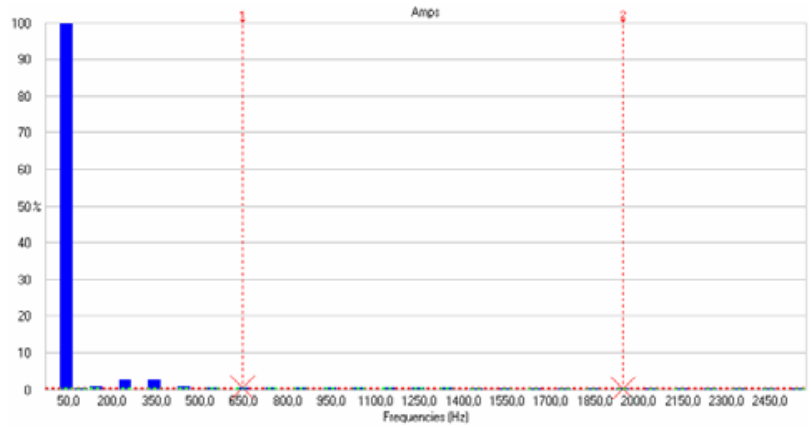

Fig. 12. Spectrum analysis of the compensated system current with $P W M$ - $16 \mathrm{kHz}$ switching technique (full bridge rectifier with a series RL load)

\section{CONCLUSIONS}

This paper presented experimental results obtained with a developed single-phase shunt active power filter laboratory prototype operating with different switching techniques: Periodic Sampling (with variable switching frequency) and Pulse Width Modulation (with constant switching frequency) for two different frequencies $(8 \mathrm{kHz}$ and $16 \mathrm{kHz})$. The shunt active filter control system is based on a simple stratagem that enables the use of the traditional p-q Theory, originally developed to three-phase power systems, in single-phase systems.

Three different types of loads were used to test the single phase active filter: a linear RL load, a rectifier with RL load, and a rectifier with $\mathrm{RC}$ load. The experimental results proved that the shunt active filter was capable of successfully compensating harmonics currents and correcting power factor for the three switching approaches used.

It was possible to conclude that the active filter switching losses for the operation with Pulse Width Modulation - at the higher fixed frequency $(16 \mathrm{kHz})$, were always substantially greater than for the other approaches. Besides, this approach did not lead to the best results in terms of reducing the source current THD in all cases (the Periodic Sampling - with variable switching frequency - was slightly better in the case of the rectifier with RL load). From these results, it can be taken the conclusion that variable switching frequency techniques should not be discarded as a solution to shunt active filters without analyzing all important points, being the system efficiency one of them.

\section{ACKNOWLEDGMENT}

This work was supported by the FCT (Fundação para a Ciência e Tecnologia), project funding POCTI/ESE/41170/2001 and POCTI/ESE/48242/2002. The authors are also grateful to PRIME (Programa de Incentivos à Modernização da Economia) for funding the Project SINUS. Luís F. C. Monteiro is supported by the Programme Alßan, the European Union Programme of High Level Scholarships for Latin America, scholarship no. E06D103177BR.

\section{REFERENCES}

[1] L. Gyugi and E. C. Strycula, "Active AC Power Filters", IEEE-IAS Annual Meeting Record, 1976, pp. 529-535.

[2] H. Akagi, Y. Kanazawa, A. Nabae, "Generalized Theory of the Instantaneous Reactive Power in Three-Phase Circuits", IPEC'83 - Int. Power Electronics Conf., Tokyo, Japan, 1983, pp. 1375-1386.

[3] H. Akagi, Y. Kanazawa, A. Nabae, "Instantaneous Reactive Power Compensator Comprising Switching Devices without Energy Storage Components", IEEE Trans. Industry Applic., vol. 20, May/June 1984.

[4] E. H. Watanabe, R. M. Stephan, M. Aredes, "New Concepts of Instantaneous Active and Reactive Powers in Electrical Systems with Generic Loads", IEEE Trans. Power Delivery, vol. 8, no. 2, April 1993, pp. 697-703.

[5] M. Aredes, E. H. Watanabe, "New Control Algorithms for Series and Shunt Three-Phase Four-Wire Active Power Filters", IEEE Trans. Power Delivery, vol 10, no. 3, July 1995, pp. 1649-1656.

[6] S. Buso; L. Malesani; P. Mattavelli; Comparison of Current Control Techniques for Active Filter Applications; IEEE Transactions on Industrial Electronics, vol. 45, Issue 5, Oct. 1998; Page(s):722 - 729. 